\title{
Strategic Response Hierarchies as Reaction to EnVIRONMENTAL Threat
}

\author{
Marshall Schminke \\ Creighton University \\ Omaha, Nebraska
}

To perform effectively, an organization must match its capabilities to its constantly changing environment. However, little research focuses on the dynamic processes by which organizations make these adaptive decisions. This research develops and tests a hierarchical model of organizational response to environmental threat. It suggests that organizations invoke preexisting sets of response programs to deal with familiar threats, and that these programs emerge in a predictable, hierarchical order.

\section{Response Programs}

When an air-raid siren sounds, the members of a military installation initiate a set of complex activities. The unit members need not discuss and plot a unique set of strategies in each instance, but rather draw on a well-learned set of programs designed to fit the situation in which they find themselves. In fact, under air raid conditions, the lost time involved in attempting to plot a unique, optimal reaction could well lead to tragic results.

In many cases firms respond and react similarly to cues from their environment. Often these events consist of situations the organization has experienced in the past. The prudent organization develops a repertoire of strategic response programs-prepackaged sets of actions to be implemented upon detection of particular, recurring, environmental cuesto deal with such shocks.

These response programs can take on many forms. For example, Staw, Sandelands and Dutton (1981) model a number of internal organizational responses to threat, one of which reflects the organization's attempts to increase operating efficiencies. Consistent with other research (Koberg 1987; Miller and Friesen 1980; Tushman and Romanelli 1985) the present paper suggests that firms do not execute these reactions randomly but rather in a predictable, hierarchical fashion. For example, in the case of a manufacturing firm, the hierarchy of responses to threat might appear as follows:

(1) Do nothing.

(2) Decrease labor costs through short term workforce layoffs.

(3) Increase short term financial liquidity through more aggressive collections.

(4) Decrease inventory levels.

(5) Decrease plant and equipment levels.

A manufacturing firm might cut back on overtime nearly by fiat, more quickly and easily than it could collect overdue receivables and marginal accounts. In times of decline, especially during severe industry-wide shocks, excess inventory could be very difficult to dispose of, and the sale of plant and equipment would likely be the most difficult response of all. The precise ordering of the responses would not be the same in all 
firms or industries, of course (e.g., steel mills and candy manufacturers), but the hierarchy reflects a range of relative difficulty and expense involved in each action. Further, within each category of responses-employment cutbacks vs. fixed asset reduction, for example-predictable sub-hierarchies also exist. The next section outlines the means by which these hierarchies may be mapped and tested.

\section{Mapping Response Hierarchies}

To determine whether response programs exist and the extent to which firms employ them, two factors are necessary. The first is an observable set of responses for which a hierarchical order can be predicted and traced over time. In this study those responses are changes in employment levels. The second necessary factor is an environmental shock, familiar to and identifiable by the firms, for which standard response routines could exist. In this study that shock is recession.

Many organizational responses such as the commission of illegal acts are not readily observable (Staw and Szwajkowski 1975). However, tracing firms' response hierarchies requires that we focus on those that are. Firms' adjustment of employment levels provides one such measure. This study examines the degree to which firms cut back in four distinct employment categories in response to recession:

(1) Overtime hours of production workers

(2) Average weekly hours of production workers

(3) Total number of production workers

(4) Total number of supervisory workers

A predictable hierarchy of responses exists among these variables; it appears as follows:

(1) Decrease overtime hours of production workers. For a manufacturing organization, decreasing overtime hours should be the easiest, quickest, and most cost-effective method of decreasing employment expenses, as the overload of labor hours implemented during prosperous times is pared back. As long as some workers still earn overtime wages-lypically at least fifty percent higher than base wages-an incentive exits to cut back on these relatively expensive overtime hours rather than cutting into other workers' regular hours.

(2) Decrease average regular weekly hours of production workers. However, as the recession develops, merely cutting back overtime hours may not provide sufficient savings. Suppose a firm determines that an additional forty hours per week of labor cutbacks are required. It may respond by laying off one worker entirely or by cutting back each of forty workers to thirty-nine hours per week. The latter is a common practice, at least in the early stages of cutbacks. The company may achieve similar results by invoking mandatory vacation periods, leaves, and so on. Either approach avoids actual layoffs, which may be costly in terms of unemployment benefits and union grievances. Even more significant may be the demonstrated effects of layoffs on the survivors of those layoffsthose who retain their jobs. Research shows that commitment, morale and productivity of the surviving workers may decline after layoffs (Brockner 1992; Brockner, et al. 1987) generating an additional cluster of indirect expenses related to the layoffs. Other dysfunctional effects of declining organizational size-as indicated by employment levels (Free- 
man and Hannan 1975)-include increased conflict, reduced flexibility, increased scapegoating, loss of leader credibility, as well as declining innovativeness, participation, and long-term planning (Cameron, Whetten and Kim 1987; Cameron, Kim and Whetten 1987). The astute firm will consider the entire package of costs-direct and indirect-of a particular employment policy. The net effect is that decreasing the average weekly hours across employees is likely to be a less costly way to reduce labor expense than complete worker layoffs.

(3) Decrease total number of production workers. As the recession develops more fully, and extra shifts or entire plants are idled, full layoffs must be invoked and the total number of production workers on the payroll will decrease. This is a difficult and costly process for the organization, especially in situations where labor unions are strong and job security has been a major concern in contract negotiations. Further, the dysfunctional effects of decline cited above have been shown to be strongest under conditions of large layoffs (Cameron, Whetten and Kim 1987). Facing this, firms will resort to wholesale layoffs only after other reasonable alternatives have been exhausted.

(4) Decrease total number of supervisory workers. Supervisory workers represent the final fatalities of the firm's search for increased labor efficiencies in response to the recession. Research demonstrates that administrators added during times of prosperity are among the final victims of layoffs in times of decline (Freeman and Hannan 1975; Miller and Friesen 1980).

The shock to which firms are responding in this study is recession, a shock that is both familiar and identifiable. From 1945 to 1980, the U.S. economy suffered six separate recessions, the first five of which were of similar duration, lasting from eight to twelve months. These five provided firms with repeated opportunities to develop sets of employment programs to deal effectively with cyclical, short-term, recessionary decline.

The sixth recession (1973-1974) was far more intense than the previous five, lasting eighteen months, and is the focus of this study. It has been described as a "prolonged agony" (Egan and Weiner 1990) as contrasted with the earlier "three quarter blips" (Egan and Weiner 1990) like the recession of 1970. (Of the two more recent recessions-19801982 and 1990-1991-neither provides a clean contrast between a string of similar shocks followed by an aberrant, severe shock.)

Upon detecting the threat of decline, firms should employ the response programs developed in the five previous recessions, since at its outset they have no reason to believe this threat will differ significantly from earlier threats. However, these established programs would be inadequate to cope with the severity and duration of the harsh 19731974 recession. As a result, we expect that the initial responses will eventually be abandoned and a new set enacted. Each of these responses and changes in responses should occur in a predictable fashion.

This sixth recession provides a view of whether (1) response programs developed during the first five recessions were implemented, (2) whether they were enacted in the predicted order, and (3) whether firms came to recognize the recession as atypical and as a result, implemented a new, more severe, set of response strategies. In most cases, this updated response will reflect many of the characteristics of the first as firms facing 
novel problems engage in what Cyert and March (1963) referred to as a problemistic search.

Under these conditions, most firms demonstrate tendencies to search in the neighborhood of current problems for potential solutions to new problems. That is, before engaging in zero-based solution generation-a costly and time consuming process-organizations explore their surroundings and histories for clues about prior problems whose successful solutions might provide for the basis of new solutions. In this case, reactions that worked well in typical recessions might be expected to work well in severe recession, if ratcheted up in intensity to match the intensity of the environmental shock.

The following hypotheses formalize these assertions:

Hypothesis 1: In response to the threat of recession, firms will implement strategic response programs to decrease labor costs.

Hypothesis 2: These response programs will be implemented in the following hierarchical order: Decrease overtime hours, decrease average weekly hours, decrease production workers, decrease supervisory workers.

Hypothesis 3: At a point at which the organizational decline is recognized as atypically severe, initial original response programs will be abandoned in favor of new, more extreme, measures.

Hypothesis 4: This second set of response programs will follow the same hierarchical order as the first: Decrease overtime hours, decrease average weekly hours, decrease production workers, decrease supervisory workers.

\section{Methods}

\section{Sample}

A sample of twenty-five industrial manufacturing and retailing groups was randomly selected from the U.S. Bureau of Labor Statistics' (BLS) monthly publication Employment and Earnings. Appendix 1 lists the industry groups and their SIC codes. (Note: The BLS does not release employment data for individual organizations but aggregates data at the 2-digit or 3-digit SIC code level. However, this creates a level-of-analysis concern in that our thinking about responses to environmental threat was carried out at the firm level, while the analyses below are executed at the industry level. The reader is cautioned to keep this in mind during each set of analyses that follows.)

\section{Measures}

Environmental Threat. Examining firms' response to environmental threat requires an indication of the onset, duration, and the intensity of the shock. Of course, different industries track different indices to determine the short and long term outlook for their markets. A variety of economic factors like money supply and housing starts as well as industryspecific measures like inventories and orders might be tracked by firms attempting to catch a glimpse of the future. However, for this analysis we cannot hope to track all indices employed by all firms across several industries. What is needed is a single index that captures a wide range of information about business conditions across a number of industries. 
For American corporate organizations whose common stock is publicly traded, such a measure is the market price of common stock or market indices derived from individual stock prices. ${ }^{1}$ These stock indices provide a useful measure of anticipated environmental shock to a firm. A decline in the price of a firm's stock indicates that analysts and investors in the financial markets have perceived some actual or potential negative shock to the company such as increased interest rates, international unrest, impending recession, and so on. ${ }^{2}$ The stock market traditionally acts as a leading indicator, providing firms with advance notice of impending economic decline. Therefore, it provides a better indicator of the point at which firms, analysts, and investors first detect the threat of decline than do the Gross Domestic Product (GDP) (then, GNP) figures that determine the technical beginning and end of recessionary periods themselves. In this case, the Standard \& Poor's 500 Index began its grand decline in January 1973, ten months prior to the onset of the actual recession. Likewise, it began to recover in December 1974, months before the technical end of the recession. 3

Organizational Response. Four categories of monthly employment data were gathered for each of the 25 industry groups from unpublished, seasonally-adjusted U.S. Bureau of Labor Statistics employment data for the period 1972-1977. ${ }^{4}$ Both the severity and the duration of the responses were calculated for each of the following:

(1) Average overtime hours (OT) per production worker.

(2) Average weekly hours (AH) (non-overtime) per production worker.

(3) Total production workers (PW) employed.

(4) Total supervisory workers (SW) employed.

A smoothing program was applied to the data to depict better the underlying patterns. 5 The smoothed series-the response curves-were plotted and several critical points (A,B,C,D,R) were identified, as shown in Figure 1. For illustrative purposes, consider the response curve for average overtime hours in industry $X$. It shows the pattern of increases and decreases in OT hours in industry $\mathrm{X}$ before, during, and after the recessionary period. Point $R$ represents January, 1973, the onset of the detected recession as indicated by the S\&P 500 Index. As would be expected, employment levels were typically rising during the pre-recession period.

\section{Figure 1: Sample "Response Curve" for Overtime Hours}

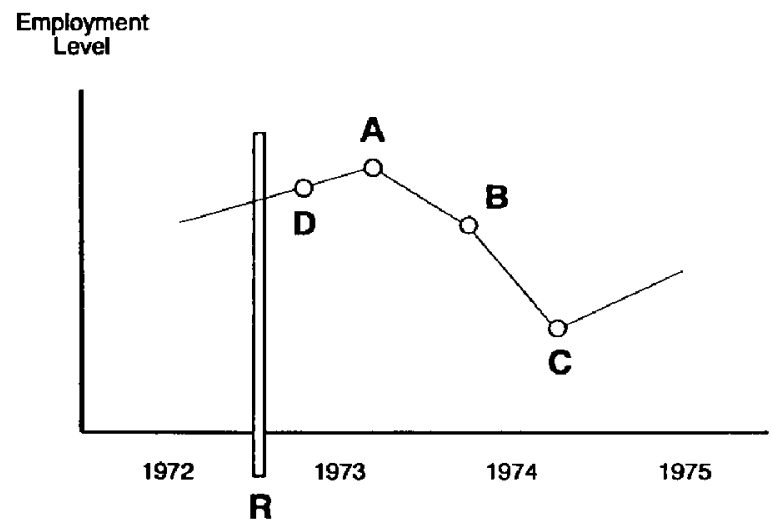


Overtime hours peaked at Point A, some months after the onset of the shock This point represents the industry's initial reaction to the shock, the point at which OT hours began to decline. Plotting Point A generates two values: the month at which the response occurred (MonthA) and the number of OT hours per employee during that month (ValueA). Point $\mathrm{D}$, the point six months prior to the initial industry reaction, likewise yields MonthD and ValueD.

Point $\mathrm{C}$ indicates the point at which the response curve reached a minimum value. It denotes the end of the industry cutback responses, as overtime hours again began to rise. Point $\mathrm{C}$ also yields two critical values, MonthC and ValueC.

Point B indicates the onset of the second, more severe, response program. It is the point at which the smoothed response curve made its most pronounced inflection-without turning upward-between points $A$ and $C$. In situations where no inflection point was identifiable, the midpoint between points $\mathrm{A}$ and $\mathrm{C}$ was selected. Point $\mathrm{B}$ also represents two values, MonthB and ValueB.

Once the four key points were identified, the following values were calculated for each of the four employment variables.

PRESLOPE: The average change per month in the employment variable during the six months prior to Point A ((ValueA - ValueD) / 6).

LAG1: The time (in months) from the onset of the shock to the beginning of the industry's initial response (MonthA - MonthR).

DUR1: The duration of the first response program (MonthB - MonthA).

MAG1: The magnitude of the first response program ((ValueB - ValueA) / ValueA). This was the percentage change in the level of the employment variable during the first response program.

SLOPE1: The average change per month in the employment variable during the first response program ((ValueB - ValueA) / DUR1).

LAG2: The time from the onset of the recession to the beginning of the second response program (MonthB - MonthR).

MAG2: The magnitude of the second response ((ValueC - ValueB) / ValueB).

SLOPE2: The average change per month in the employment variable during the second response period ((ValueC - ValueB) / DUR2).

\section{Analysis and Results}

Hypothesis 1 states that firms will react to the recession by implementing labor cutbacks in each of the four employment categories. Table 1 shows means and standard deviations for PRESLOPE and SLOPE1 for each employment variable across the 25 industries, with results of the pooled t-test comparisons of these means. PRESLOPE denotes the trend in employment levels prior to the initial reaction to the recession. SLOPE1 denotes the trend in employment levels after the initial reaction to the recession. This comparison reveals that the average OT hours during the first response program were significantly lower than those in the pre-response period. The same is true across the other three employment variables, indicating that the firms in these industries did react to the 
impending decline with responses across all employment categories. These results support Hypothesis 1.

Table 1: Test of Hypothesis 1

\begin{tabular}{lrlrl} 
& \multicolumn{1}{c}{ PRESLOPE } & \multicolumn{1}{c}{ SLOPE1 } & T-VALUE (D.F.) \\
\hline & MEAN (S.D.) & MEN (S.D.) & \\
& & & & \\
Overtime Hours & .125 & $(.127)$ & $-.057(.072)$ & $5.46(48) * * * *$ \\
Weekly Hours & .198 & $(.300)$ & $-.046(.067)$ & $3.97(48) * * *$ \\
Prod. Workers & .819 & $(.690)$ & $-.331(.586)$ & $6.23(48) * * *$ \\
Super. Workers & $1.04(1.780)$ & $-.729(2.28)$ & $3.06(48) * *$ \\
& & &
\end{tabular}

Hypothesis 2 states that the response programs will be implemented in a particular hierarchical order; cutbacks should be implemented first in overtime hours (OT), followed by average weekly hours (WH), total production workers (PW), and finally, total supervisory workers (SW). This suggests that the time lag from Point $\mathrm{R}$ to the onset of the response program (LAG1) will be shortest for OT, followed by WH, PW, and SW, respectively. Table 2 shows results of a rank ordering of the industries' mean LAG1 for each of the employment categories.

Table 2: Test of Hypothesis 2

\begin{tabular}{|c|c|c|c|c|c|}
\hline \multicolumn{2}{|c|}{$\begin{array}{l}\text { TEST OF LAG1: } \\
\text { (MEAN MONTHS TO 1st REACTION) }\end{array}$} & \multicolumn{4}{|c|}{$\begin{array}{l}\text { SIG. OF DIFFERENCES } \\
\text { BETWEEN MEANS: }\end{array}$} \\
\hline Av. Overtime Hrs. (OT) & 6.16 & & $\mathrm{AH}$ & PW & SW \\
\hline Av. Weekly Hrs. (AH) & 6.76 & OT & - - & ** & ** \\
\hline Tot. Prod. Workers (PW) & 12.20 & SW & ** & * & \\
\hline Tot. Super. Workers (SW) & 14.72 & PW & ** & & \\
\hline
\end{tabular}

Note: ${ }^{*}=\mathrm{p}<.05,{ }^{* *}=\mathrm{p}<.01,--=$ not significant

Results in Table 2 support Hypothesis 2. Lag times for each employment variable emerge in the predicted order. Cuts in overtime hours occurred slightly more than six months after Point $R$. Cuts in average weekly hours began after nearly seven months. Over twelve months passed before total number of production workers began to fall, and nearly fifteen months before total number of supervisory workers began to decline.

Table 3 also shows results of a simultaneous paired comparison procedure that tests whether the differences between these mean lag times were significant. ${ }^{6}$ With the exception of the OT-AH pairing, each response was instituted at a significantly later time than its predecessor. These results provide stronger support for Hypothesis 2. 
Hypothesis 3 suggests that upon discovering that the environmental shock is more severe than the current set of response programs can accommodate, organizations will invoke a second, more severe set of response programs. To test whether more severe changes were employed, two sets of comparisons were performed for each employment variable. First, SLOPE1 and SLOPE2 were compared. SLOPE1 values show employment trends during the first response period, and SLOPE2 values show employment trends after implementation of the second set of response programs. Second, MAG1 and MAG2 were compared, assessing the difference in relative magnitude of the cutbacks in each period. Table 3a shows means and standard deviations for SLOPE1, SLOPE2, MAG1, and MAG2 values as well as results of pooled t-tests of differences between the means.

\section{Table 3: Test of Hypothesis 3}

Table 3a:

SLOPE1

MEAN (S.D.)
SLOPE2

MEAN (S.D.)

Overtime Hours

Weekly Hours

Prod. Workers

Super. Workers

$\begin{array}{ll}-.057(.072) & -.159(.105) \\ -.046(.067) & -.214(.151) \\ -.331(.586) & -1.52(1.20) \\ -.729(2.28) & -1.02(2.88)\end{array}$

Overtime Hours

Weekly Hours

Prod. Workers

Super. Workers
MAG1

MAG2

$\begin{array}{ll}-.157(.149) & -.409(.171) \\ -.017(.022) & -.045(.029) \\ -.030(.064) & -.115(.085) \\ -.021(.057) & -.050(.071)\end{array}$

$4.84(48)$

$3.97(48) * * *$

$3.92(48) * * *$

N.S.

Note: ${ }^{*}=\mathrm{p}<.05,{ }^{* *}=\mathrm{p}<.01,{ }^{* * *}=\mathrm{p}<.001,{ }^{* * * *}=\mathrm{p}<.0001,,^{-}=$not significant

Table 3b:

TEST OF DUR1:

(MEAN DUR. OF 1st REACTION)

Av. Overtime Hrs. (OT)

Av. Weekly Hrs. (AH)

13.11

13.20

Tot. Prod. Workers (PW)

13.00

Tot. Super. Workers (SW) - - -

SIG. OF DIFFERENCES

BETWEEN MEANS:

Note: ${ }^{*}=\mathrm{p}<.05,{ }^{* *}=\mathrm{p}<.01,{ }^{* * *}=\mathrm{p}<.001,{ }^{* * * *}=\mathrm{p}<.0001,--=$ not significant 
Results in Table 3a indicate a marked change in employment policies between the two periods, both in trends (slopes) of employment and in the magnitude of change in employment levels. The decreases in each of the employment categories that began declining the initial response period continued, but at an accelerated rate, during the second period. All differences are significant except for the decreases in SW, which had not stopped declining during this period, but the rate of decrease had not accelerated rapidly enough to create significant differences. These results support Hypothesis 3. However, since the results do not demonstrate a clear two-stage response in supervisory personnel the rest of the analysis will consider it to be a single-stage response.

A further implication of Hypothesis 3 is that if these responses are truly established programs rather than week-by-week updates reflecting companies' reactions to decline, their duration should reflect the average length of the event that they were designed to deal with. In the two-stage response demonstrated here, the duration of the first stage should correspond to the duration of the typical postwar recession. The lengths of the 1949, 1953, 1957,1960 , and 1970 recessions were $11,10,8,10$, and 11 months, respectively.

Those programs in the initial stage would reflect that time frame and were expected to run at least that long. However, they were not expected to stay in place much longer, as they were not developed to deal with severe recessions of over one year. On or about the twelfth month, firms would recognize that this shock was something out of the ordinary, abandon their initial response programs, and implement the second stage. Results in Table $3 \mathrm{~b}$ demonstrate that the average duration of each employment response was approximately thirteen months. None differed significantly from the others, further supporting Hypothesis 3.

Hypothesis 4 states that the second set of response programs will be implemented in the same hierarchical order as the first. Testing this hypothesis followed the same format as testing Hypothesis 2 with one exception. Since a clear second-stage response for SW did not appear, it was not included in the analysis. Table 4 shows results of the rankordering of LAG2 for each of the other employment variables.

\section{Table 4: Test of Hypothesis 4}

\section{\begin{tabular}{l|l} 
TEST OF LAG2: & SIG. OF DIFFERENCES
\end{tabular} (MEAN MONTHS TO 2nd REACTION) BETWEEN MEANS:}

\begin{tabular}{lr|lll}
\hline Av. Overtime Hrs. (OT) & 19.26 & AH & PW & \\
Av. Weekly Hrs. (AH) & 19.96 & OT & -- & $*$ \\
Tot. Prod. Workers (PW) & 25.20 & PW & $* *$ & \\
Tot. Super. Workers (SW) & $-\ldots$ & & &
\end{tabular}

Note: ${ }^{*}=\mathrm{p}<.05,{ }^{* *}=\mathrm{p}<.01,--=$ not significant

Results indicated that the mean values for LAG2 occurred in the predicted order. Slightly more than nineteen months passed from Point $R$ to the beginning of the second, 
more severe, response in OT cutbacks. Nearly twenty months passed before more severe cutbacks in WH began, and over twenty-five months passed before the second response in cutting back PW began. Results indicated that with the exception of the pairing between WH and OT, these differences were significant.

\section{Discussion and Conclusions}

This paper examined the processes by which firms deal with environmental threats. It tested whether firms respond with sets of preprogrammed routines-response programswhen facing these threats. It investigated whether companies across 25 industries invoked predictable sets of strategic responses in a particular hierarchical fashion. Further, it tested whether one set of routines was abandoned in favor of another upon discovery of the inappropriateness of the original package. All hypotheses were supported.

The results are significant, both theoretically and practically. We know relatively little about the way organizations manage environmental shocks, and even less about the ways in which they should. This paper sheds some light on the processes employed, suggesting that under threatening conditions, mangers employ a problemistic search. That is, for solutions to new problems, managers seek out existing programs that worked in the past on similar problems. A repertoire of response programs simplifies this search.

We commonly hear about the piffalls of "managing by putting out fires"; managers often have all they can handle simply attending to the problem of the minute. Less immediately-pressing issues like strategic planning are pushed to the background as managers employ a twine-and-bailing-wire approach to holding the firm together. Diligent environmental scanning, monitoring, assessment, and forecasting fall by the wayside as readymade response programs are pulled from the shelf, put in place, and allowed to run (a fire is doused) until it is clear they are no longer appropriate (a new fire begins). These results suggest that may be the process firms use to cope with threat. Ironically, the declining organization may be the least able to absorb the mistakes inherent in a system devoid of strategic management. Further study is needed to develop programs aimed at culling out ineffective response programs, retaining the adaptive ones, and developing systems that would aid managers in determining which are which in a particular situation.

Knowing more about how firms are likely to respond to various shocks may be useful for the strategically adept organization. It has been shown that strategic planning can provide a source of competitive advantage (Powell 1992) and a critical goal of planning is to be able to anticipate competitive responses to various market changes. These results suggest that under conditions of familiar shock, a firm might be able to predict accurately the likely responses of its competitors, buyers, and suppliers. With that ability will come first-mover advantages like increased market share (Mascarenhas 1992).

The larger issue of strategic scanning should also be noted. The present results regarding firms' use of response programs relate to a firm's scanning processes in two ways. First, an important component of the scanning process is for organizational boundary spanners to have some notion of the events to which they ought to be attending. Recog- 
nizing patterns in competitor responses would be key to formulating and executing appropriate responses. If, as these results suggest, firms tend to utilize existing routines of responses, those should be relatively easily recognized by skilled scanners. Knowing that response routines are regularly repeated should allow scarce scanning resources to be concentrated on a set of "most likely" patterns of behavior.

Second, it has been shown that effective environmental scanning and interpretation is related to better performance (Thomas, et al. 1993). The other side of this coin is that poorer scanning leads to poorer performance, which has been linked to even less attention being paid to strategic planning. Thus, a dangerous cycle has begun. To the extent that a firm is skillful in its scanning-and thus better able to detect and predict the responses of othersthe risk of further decline and the dysfunctions associated with it is minimized.

However, several caveats remain. Much of the discussion of the issues at the heart of this research was at the firm level, but analysis proceeded at the industry level. While industry-level data reflect the aggregation of individual firms' responses, and strong crossindustry results boost confidence in their generalizability, industry data miss much of the potential richness of firm-level data. In addition, industry-level data do not allow for the sort of between-industry analyses that would tell us about the specific differences that might be expected from one industry to the next. Responses in recession-vulnerable industries like building materials may be quite different from those that are more recession-resistant like food products. However, it should be noted that these employment responses were strong and stable enough across disparate industries to yield significant results even at this macro-level of analysis. Therefore, it is likely that the more homogeneous within-industry responses would be even more pronounced and traceable.

Second, this paper examined only a small subset of possible responses to a single type of environmental change. It would be interesting and useful to examine additional types of response hierarchies, to determine the extent of their predictability and stability. In addition, this paper shed little light on what additional types of responses exist in these and other organizations and whether the programs are common across alternative forms of environmental shocks.

A third set of questions concerns the conditions under which these response programs might differ. For example, the degree to which a firm is buffered from environmental shock may affect the type, magnitude, and speed of response programs it invokes. Specifically, those organizations or industries that are relatively well buffered from the environment may respond to market-wide shock much more slowly and to a much lesser degree than organizations or industries whose businesses are more volatile. For example, well-buffered firms may be able to make more effective use of response programs as reactions to decline in that implementing the "wrong" program would carry less severe results. Less-buffered firms may need to decrease their dependence on prepackaged programs, in that they are especially vulnerable to these same potential mistakes.

It may also be the case that new employment alternatives have emerged that would alter the nature of the particular employment hierarchy tested here. Corporate restructuring has altered the face of many organizations in the past decade, especially in middle management, as increased outsourcing, subcontracting, and use of temporary workers has 
pushed the risk of carrying employees during economic downturns out to satellite firms. It is possible that a revised set of programs would include cutbacks in these areas as well at the traditional employee pools.

Finally, the role of organizational and managerial learning (Lant and Milliken 1992) in these response processes needs to be examined. The present research assumes that organizational response programs grow from previous organizational experience, either that of the firm or that of the individuals the firm might hire from experienced firms. The "liability of newness" effect (Bruderl and Schussler 1990) that relatively young firms are generally more vulnerable-may have to do with their inability to make good decisions regarding appropriate responses to what they view as novel events. Their more experienced counterparts are able to implement established response programs more quickly, freeing up scarce resources for other needs and addressing the impending problem in a more timely fashion.

The process by which well-learned response programs are updated or disposed of should also be addressed. The severe shock that was the focus of this study followed a series of mild, relatively similar, recessions that allowed firms to develop programs to deal with a "typical" recession. We do not know much about the process by which organizations cope with a series of atypical shocks or a change in what is believed to be typical. For example, since the 1973-1975 recession the U.S. has experienced two longer recessionary periods than were typical in the post-war era. The effect that the severe 1973-1975 recession and the later double-dip shocks have had on the established response routines provides an interesting avenue for future research.

\section{Guidelines for Managers}

Several important lessons for managers may be drawn from this study. They involve the strategic benefits of recognizing and utilizing the response patterns of one's own firm as well as those of one's competitors. First mover advantages go to firms whose responses are both timely and accurate. This final section outlines the process by which managers might adopt some of these ideas for their own strategic benefit.

(1) Identify the Critical Success Factors (CSFs) for your industry. Experts in most industries are able to identify a small set of numbers that conveys an accurate picture of the health of firms in that industry. Typically, these are underlying operational figures rather than pure financial (outcome) statistics. For example, every carrier in the airline industry tracks and attends to passenger load factor, the percentage of available seats that are actually sold. Keeping planes full (or as nearly so as possible) is key to success in this industry. Retailers track inventory turnover, restaurants track food cost as a percentage of sales, and large brewers track market share. The specific categories differ across industries, but once identified, five or six CSFs provide a great deal of information about the firms in that industry. They also provide the basis for tracking the response hierarchies in that industry.

(2) Identify threats and shocks common to the industry. This paper examined recession, and for some industries that constitutes a-or even the-major threat. For other busi- 
nesses, fuel prices, interest rates, international instability, or even the weather might be more salient threats. To identify the most pronounced response programs, these threats should include only recurring events for which firms would have well-developed, prepackaged responses.

(3) Gather historical data. Once CSFs and recurring threats have been identified, a history must be drawn. CSF information for each competitor is gathered over a span of time in which industry threats emerged and subsided several times. Part of this process includes identifying points analogous to those in Figure 1: onset of the shock, inflection points, and so on. As the history is drawn, care should be taken to collect relevant control factors like firm size, severity of shock, and so on, to be used in the analysis.

(4) Include your firm in this process. Like individuals, many firms may be more aware of others' habits than their own. Throughout the process, self-analysis and self-evaluation are vital.

(5) Evaluate the effectiveness of the response programs. Even within a single industry, firms will differ in terms of their responses to threats. Some may implement layoffs while others cut back on research and development spending. By assembling a lengthy industry history we may learn not only what competitors did, but what worked. Grossly inappropriate strategic moves are often self-correcting (firm death) but in most industries a range of strategic responses might be supported. The point is to determine which are most effective.

(6) Assess your firm's vulnerability to the shocks. Not all organizations are equally vulnerable to a given threat. Within-industry differences in strategic posture might soften or enhance the effect of a particular shock. In addition, something of a compensatory effect exists between resources devoted to buffering your firm from shock (e.g., outsourcing components even at slightly higher cost) and those devoted to managing the threat (e.g., scanning, analysis, and corrective action expenses). By prioritizing the threats to which a firm is most vulnerable, managers might make better use of limited resources.

(7) Adjust or create response programs accordingly. Steps one through six are not the firm's solution. Rather, they put the firm in a position to create solutions. Carefully executed, steps one through six will provide a manager with a clear picture of patterns of responses to common environmental shocks, by his or her own firm as well as competitors, over time. At this point, a manager should understand the nature of the responses, as well as their predictability and effectiveness. Once those three pictures emerge, it is relatively simple to evaluate one's own existing set of programs. It would not be unusual to expose over- or under-allocation of resources across these programs. That is, the $80 / 20$ rule (that $80 \%$ of the action comes from $20 \%$ of the cases) may be in effect here. If so, it would serve the strategic manager well to know of it and to reallocate adaptation resources accordingly.

(8) Explore related industries. A great deal can be learned from examining one's own industry, but additional insights may emerge from taking a close look at similar or related industries. Much as technology transfers between industries or economies, strategies also find their way to arenas outside those in which they were born. Sometimes those moves happen accidently; other times they are managed. The prudent strategic manager 
will look beyond his or her own industry in search of ideas that might lead to competitive advantage.

In The Art of War, Sun Tzu tells us "What enables the wise sovereign and the good general to strike and conquer, and achieve things beyond the reach of ordinary men, is foreknowledge" (Sun Tzu 1983). A great deal of knowledge can be gained from studying the history of one's firm, one's industry, and related industries. That study is made more efficient by knowing what information to gather and what sort of patterns to look for after gathering it. This approach to environmental scanning, information gathering, response mapping and strategic sense-making may yield significant strategic benefits.

\section{Endnotes}

1. Reasonable theoretical basis exists for using a market index as a leading economic indicator. The efficient market hypothesis (EMH) of finance theory suggests that the current market price of a stock reflects all publicly available and relevant information regarding the value of the firm (Brigham and Gapenski 1991). This information includes company earnings records and announcements, economic conditions, world news, and any other conditions that the buyers and sellers in the stock market feel will affect its present or future performance. According to the EMH, stock prices reflect new information very quickly-just how rapidly is a point of some debate-but most evidence suggests these markets are quite efficient (Arrow 1982).

2. It is not necessary to monitor all environmental events in order to identify impending environmental shock, since the financial markets perform the task for us. (It is estimated that each major stock is tracked by approximately 1000 industry analysts at banks, insurance companies, investment firms, and brokerage houses across the country and around the world (Brigham and Gapenski 1991).) In fact, it is not necessary even to agree upon or fully understand what the shock is or what caused it; we need only observe the change in the index to detect negative news. We may measure the intensity of the shock without fully understanding its cause in much the same way that we may measure temperature without an understanding of molecular theory. This holds for industry-level and market-level indices as well as individual stocks. The Standard and Poor's 500 Composite Index, for example, identifies market-wide shocks to American corporations and industries it represents.

3. It is not the position of this paper that a single market index like the S\&P 500 is what firms are actually tracking, or that it will do a better job of predicting impending shocks to a firm or industry than the numerous indices they do follow. However, it does provide a useful proxy for the many individual indices firms and industries do, in fact, track.

4. This "unpublished" raw data is available from the BLS, but does not appear in any periodical BLS publication like Employment and Earnings.

5. This resistant smoothing program replaces each data value with the median of data values immediately before and after it. Resistant smoothers were built up by successive applications of simple smoothers (running medians of 4 , then 2 , then 5 , then 3 ) followed 
by a Hanning process (a running average computed as $z(t)=.25 y(t-1)+.5 y(t)+$ $.25 y(t+1))$. The smoothing program executed this sequence twice. See also Velleman (1980).

6. Tukey's paired comparison procedure tests for differences between multiple means, a procedure not possible with simple paired t-tests.

\section{References}

Arrow, KJ. 1982. "Risk Perception in Psychology and Economics." Economic Inquiry 20: 1-9.

Brigham, E.F. and L.C. Gapenski. 1991. Financial Management. Chicago: The Dryden Press.

Brockner, J. 1992. "Managing the Effects of Layoffs on Survivors." California Management Review 34: 9-28.

Brockner, J., S. Grover, T. Reed, R. DeWitt, and M. O'Malley. 1987. 'Survivors' Reactions to Layoffs: We Get By with a Little Help for Our Friends." Administrative Science Quarterly 32: 526-541.

Bruderl, J. and R. Schussler. 1990. "Organizational Mortality: The Liability of Newness and Adolescence." Administrative Science Quarterly 35: 530-547.

Cameron, K.S., M.U. Kim, and D.A. Whetten. 1987. "Organizational Effects of Decline and Turbulence." Administrative Science Quarterly 32: 222-240.

Cameron, K.S., D.A. Whetten, and M.U. Kim. 1987. "Organizational Dysfunctions of Decline." Academy of Management Journal 30: 126-138.

Cyert, R. and J. March. 1963. A Behavioral Theory of the Firm. Englewood Cliffs, NJ: PrenticeHall.

Egan, J. and D.P. Wiener. 1990. "Fishing for Good Deals." U.S. News and World Report Sept. 24: $82-90$.

Fama, E.F. 1976. Foundations of Finance. New York: Basic Books, Inc.

Freeman, J. 1979. "Going to the Well: School District Administrative Intensity and Environmental Constraint." Administrative Science Quarterly 24: 119-133.

Freeman, J. and M.T. Hannan. 1975. "Growth and Decline Processes in Organizations." American Sociological Review 40: 215-228.

Koberg, C.S. 1987. "Resource Scarcity, Environmental Uncertainty, and Adaptive Organizational Behavior." Academy of Management Journal 30: 798-807. 
Lant, T.K. and F.J. Milliken. 1992. "The Role of Managerial Learning and Interpretation in Strategic Persistence and Reorientation: An Empirical Exploration." Strategic Management Journal 13: 585-608.

Mascarenhas, B. 1992. "First-Mover Effects in Multiple Dynamic Markets." Strategic Management Journal 13: 237-243.

McKinley, W. 1987. "Complexity and Administrative Intensity: The Case of Declining Organizations." Administrative Science Quarterly 32: 87-105.

Miller, D. and P.H. Friesen. 1980. "Momentum and Revolution in Organizational Adaptation." Academy of Management Journal 23: 591-614.

Powell, T.C. 1992. "Strategic Planning as Competitive Advantage." Strategic Management Journal 13: 551-558.

Staw, B.M., L.E. Sandelands, and J.E. Dutton. 1981. "Threat-Rigidity Effects in Organizational Behavior: A Multilevel Analysis." Administrative Science Quarterly 26: 501-524.

Staw, B.M. and E. Szwajkowski. 1975. "The Scarcity-Munificence Component of Organizational Environments and the Commission of Illegal Acts." Administrative Science Quarterly 20: 345-354.

Sun Tzu. 1983. The Art of War. Ed. J. Clavell. New York: Dell Publishing.

Thomas, J.B., S.M. Clark, and D.A. Gioia. 1993. "Strategic Sensemaking and Organizational Performance: Linkages Among Scanning, Interpretation, Action, and Outcomes." Academy of Management Journal 36: 239-270.

Tushman, M.L. and E. Romanelli. 1985. "Organizational Evolution: A Metamorphosis Model of Convergence and Reorientation." Research in Organizational Behavior. Eds. L.L. Cummings \& B.M. Staw. Greenwich, CT: JAI Press.

Velleman, P.F. 1980. "Definition and Comparison of Robust Nonlinear Data Smoothing Algorithms." Journal of the American Statistical Association 75: 609-615. 


\section{Appendix 1: Inventory of Industrial Groups}

\section{SIC Industry}

120 Bituminous coal

130 Oil and gas extraction

150 General building contractors

160 Heavy construction contractors

207 Confectionery and related products

208 Beverages

211 Cigarettes

220 Textile mill products

230 Apparel and other textile products

251 Household furniture

260 Paper and allied products

283 Drugs

301 Tires and inner tubes

331 Blast furnace / basic steel products

352 Farm machinery

353 Construction and related machinery

354 Metalworking machinery

363 Household appliances

367 Electronic components and accessories

372 Aircraft and parts

$374 \quad$ Railroad equipment

394 Toys and sporting goods

$530 \quad$ Retail variety stores

$540 \quad$ Retail food stores 